DOI 10.18551/rjoas.2020-02.02

\title{
FRESH SEMEN QUANTITY AND QUALITY OF MADURA BULLS IN RELATION TO AGE
}

\author{
Kurniawan Muhammad Briliansyah, Isnaini Nurul* \\ Department of Animal Production, Faculty of Animal Science, University of Brawijaya, \\ Malang, Indonesia \\ Kholifah Yayuk \\ Singosari National Artificial Insemination Center, Malang, Indonesia \\ *E-mail: nurulisna@ub.ac.id \\ ORCID: 0000-0002-4146-0105
}

\begin{abstract}
This study was carried out to evaluate the effect of age on the fresh semen quantity and quality of Madura bulls. One hundred and two semen samples collected from three Madura bulls aged at 4, 8 , and 12 years old (34 samples of each bull) were involved in this study. All data were analyzed using one-way analysis of variance followed by post-hoc Duncan test. Interrelationship among semen volume, sperm concentration, and individual sperm motility was analyzed using the Pearson correlation test. Results showed that the semen volume significantly increased $(P<0.05)$ along with the increasing age. On the other hand, sperm concentration significantly reduced $(P<0.05)$ from 4,8 , to 12 years old. At 4 and 8 years old, total sperm production was significantly higher $(\mathrm{P}<0.05)$ compared to those at 12 years old. Whereas, the individual sperm motility of bulls aged at 8 and 12 years old were higher $(\mathrm{P}<0.05)$ than those at 4 years old. In terms of total motile sperm production, the 8 years old bull was superior $(\mathrm{P}<0.05)$ to that of 4 and 12 years old bulls. Semen volume had a negative correlation $(-0.39 ; \mathrm{P}<0.001)$ with sperm concentration. Whereas, semen volume had a positive correlation $(0.50 ; \mathrm{P}<0.001)$ with individual sperm motility. On the other hand, sperm concentration had no significant correlation $(P>0.05)$ with individual sperm motility. It could be concluded that age greatly affects the fresh semen quality of Madura bulls. The fresh semen quantity and quality of Madura bulls reaching optimum performance at 8 years old.
\end{abstract}

\section{KEY WORDS}

Artificial insemination, fertility, Indonesian local cattle, total motile sperm, semen cryopreservation, tropical region.

The rapid population growth, along with the increase in economic status and the change in consumer preferences, are improving the beef demand in Indonesia. In 2020, it was predicted that the human population reached about 274 million, while average beef consumption about $3.36 \mathrm{~kg}$ per capita per year (Agus and Widi, 2018). On the other hand, the beef cattle population in Indonesia is about 17.05 million head with beef production of 496.30 thousand tons (DGLAH, 2018). The current local beef production can only supply about $45 \%$ of national demand, while another $55 \%$ came from imported sources (Agus and Widi, 2018). For that reason, efforts are needed to accelerate the local cattle population to meet national beef demand and achieve beef self-sufficiency.

Madura cattle is one of the Indonesian local cattle which is widely reared in East Java, especially in Madura Island. This cattle is a composite breed developed from Ongole cattle and Bali cattle (Bos javanicus) that has undergone for hundred years to reach remarkable uniformity (Sutarno et al., 2015; Widyas et al., 2018). Madura cattle have good genetic quality and have several advantages, including easily to adapt to tropical conditions and lowquality feed, as well as having fewer feed requirements as compared to imported cattle.

One effort to increase the Madura cattle population is the development of smallholder breeding programs integrated with industrial-scale breeding programs with the use of artificial insemination technology. The purpose of artificial insemination is to help farmers get superior 
stocks that have high productivity cheaply and easily. The quantity and quality of spermatozoa highly determine the success of artificial insemination. Several factors that influence semen quality of bulls are age, breed, season, and nutrition (Byrne et al., 2018; Felton-Taylor et al., 2020). The bull age is one of the crucial factors that influence semen production and quality (Carreira et al., 2017; Argiris et al., 2018). Until now, there is not much information about the effect of age on the semen quantity and quality of Madura bulls. Therefore, it is necessary to research the effect of age on the fresh semen quality of Madura bulls.

\section{MATERIALS AND METHODS OF RESEARCH}

The current study was carried out in Singosari National Al Center (Malang, Indonesia). Three Madura bulls were used as experimental animals. The bulls aged at 4, 8 , and 12 years old. All of the bulls were reared with similar management conditions under standard protocol in the bull station.

A total of 102 semen samples (34 samples of each bull) were included in the evaluation of fresh semen quality. Firstly, semen volume was evaluated by using a collection tube equipped with graded scale (Susilawati et al., 2018). After that, the semen sample was subjected to sperm concentration analysis by using a spectrophotometric method (Isnaini et al., 2019a). Data of semen volume was then multiplied by sperm concentration to obtain total sperm production (Isnaini et al., 2019b). Next, individual sperm motility was assessed under a light microscope with 400 times of magnification (Isnaini et al., 2019c). Data of total sperm production was then multiplied by individual sperm motility to obtain total motile sperm production (Isnaini et al., 2019a).

All data were analyzed using one-way analysis of variance followed by post-hoc Duncan test for significantly different data. Interrelationship among semen volume, sperm concentration, and individual sperm motility was analyzed using the Pearson correlation test. $\mathrm{P}<0.05$ was regarded as a significant difference.

\section{RESULTS AND DISCUSSION}

Table 1 shows the fresh semen quality of Madura bulls in relation to age. Results showed that the semen volume significantly increased $(P<0.05)$ along with the increasing age. On the other hand, sperm concentration significantly reduced $(P<0.05)$ from 4,8 , to 12 years old. At 4 and 8 years old, total sperm production was significantly higher $(\mathrm{P}<0.05)$ compared to those at 12 years old. Whereas, the individual sperm motility of bulls aged at 8 and 12 years old were higher $(\mathrm{P}<0.05)$ than those at 4 years old. In terms of total motile sperm production, the 8 years old bull was superior $(P<0.05)$ to that of 4 and 12 years old bulls.

Table 1 - Fresh semen quality (mean \pm SE) of Madura bulls in relation to age

\begin{tabular}{ccccc}
\hline \multirow{2}{*}{ Traits } & \multicolumn{3}{c}{ Bull age } & \multirow{2}{*}{ P-value } \\
\cline { 2 - 4 } & 4 years old & 8 years old & 12 years old & $<0.001$ \\
VOL & $4.55 \pm 0.26^{\mathrm{a}}$ & $6.12 \pm 0.28^{\mathrm{b}}$ & $6.85 \pm 0.18^{\mathrm{C}}$ & $<0.001$ \\
CONC & $1.05 \pm 0.06^{\mathrm{c}}$ & $0.90 \pm 0.05^{\mathrm{b}}$ & $0.54 \pm 0.02^{\mathrm{a}}$ & 0.002 \\
TOT & $4.69 \pm 0.37^{\mathrm{D}}$ & $5.46 \pm 0.41^{\mathrm{b}}$ & $3.73 \pm 0.19^{\mathrm{a}}$ & $<0.001$ \\
IMOT & $41.62 \pm 2.86^{\mathrm{a}}$ & $66.76 \pm 1.92^{\mathrm{D}}$ & $64.41 \pm 1.13^{\mathrm{D}}$ & $<0.001$ \\
TMOT & $2.13 \pm 0.27^{\mathrm{a}}$ & $3.73 \pm 0.29^{\mathrm{b}}$ & $2.43 \pm 0.14^{\mathrm{a}}$ & \\
\hline
\end{tabular}

VOL: semen volume (mlejaculate), CONC: sperm concentration (billion/ml), TOT: total sperm production (billion/ejaculate), IMOT: Individual sperm motility (\%), TMOT: total motile sperm production (billion/ejaculate).

${ }^{a-c}$ different superscript letter within the same row indicated a significant difference $(P<0.05)$.

Table 2 shows the interrelationship among the fresh semen quality of Madura bulls. Results showed that semen volume had a significant negative correlation $(P<0.001)$ with sperm concentration. Whereas, semen volume had a significant positive correlation 
$(\mathrm{P}<0.001)$ with individual sperm motility. On the other hand, sperm concentration had no significant correlation $(P>0.05)$ with individual sperm motility.

Table 2 - Interrelationship among fresh semen quality of Madura bulls

\begin{tabular}{ccc}
\hline Traits & Pearson correlation & P-value \\
\hline VOL x CONC & -0.39 & $<0.001$ \\
VOL x IMOT & 0.50 & $<0.001$ \\
CONC x IMOT & -0.09 & 0.362 \\
\hline
\end{tabular}

VOL: semen volume (ml/ejaculate), CONC: sperm concentration (billion/ml), IMOT: Individual sperm motility (\%).

The increase of the semen volume of Madura bulls from 4, 8, to 12 years old found in this study agreed with that reported by Murphy et al. (2018). In that study, the increasing bull age also followed by the increasing semen volume. The rationale of this result probably due to the continual progress of reproductive organ development as the age becomes older. Perumal et al. (2014) found that age had a positive correlation with scrotal circumference and testicular measurements. The older bulls had bigger scrotal circumference and testicular weight as compared to the younger ones (Ahmad et al., 2011; Perumal et al., 2017). The bigger reproductive organ could improve semen production potency so that the semen volume from an ejaculate will be higher. In contrast, sperm concentration has an inverse trend compared to the semen volume, in which older bulls had the lowest value compared to the younger bulls. This result maybe because of the negative correlation between semen volume and sperm concentration. Previously, Rehman et al. (2016) also recorded a negative correlation between semen volume and sperm concentration. In terms of total sperm production, this trait was tended to be increased from 4 to 8 years old but then decrease at 12 years old. This finding is in harmony with a previous study by Snoj et al. (2013), who observed that the total sperm production was increased along with the advancing age but at a certain age, this trait will be decreased. In the current study, 8 years old bull had higher individual sperm motility and total motile sperm production than 4 and 12 years old bulls. It could be stated that 8 years old is the most suitable age for semen collection of Madura bulls.

\section{CONCLUSION}

According to the results above, it could be concluded that the age greatly affects fresh semen quality of Madura bulls. The fresh semen quantity and quality of Madura bulls reaching optimum performance at 8 years old.

\section{ACKNOWLEDGMENTS}

The authors would like to thanks Singosari National Artificial Insemination Centre (Malang, Indonesia) for providing research facility support.

\section{REFERENCES}

1. Agus, A. and Widi, T.S.M. 2018. Current situation and future prospects for beef cattle production in Indonesia-A review. Asian-Australasian Journal of Animal Sciences, 31(7): 976-983.

2. Ahmad, E., Ahmad, N., Naseer, Z., Aleem, M., Khan, M.S., Ashiq, M. and Younis, M. 2011. Relationship of age to body weight, scrotal circumference, testicular ultrasonograms, and semen quality in Sahiwal bulls. Tropical Animal Health and Production, 43(1): 159-164.

3. Argiris, A., Ondho, Y.S., Santoso, S.I. and Kurnianto, E. 2018. Effect of age and bulls on fresh semen quality and frozen semen production of Holstein bulls in Indonesia. In IOP Conference Series: Earth and Environmental Science, 119(1), p.012033. 
4. Byrne, C.J., Fair, S., English, A.M., Cirot, M., Staub, C., Lonergan, P. and Kenny, D.A. 2018. Plane of nutrition before and after 6 months of age in Holstein-Friesian bulls: I. Effects on performance, body composition, age at puberty, and postpubertal semen production. Journal of Dairy Science, 101(4): 3447-3459.

5. Carreira, J.T., Trevizan, J.T., Carvalho, I.R., Kipper, B., Rodrigues, L.H., Silva, C., Perri, S.H.V., Drevet, J.R. and Koivisto, M.B. 2017. Does sperm quality and DNA integrity differ in cryopreserved semen samples from young, adult, and aged Nellore bulls?. Basic and Clinical Andrology, 27(1), p.12.

6. DGLAH (Directorate General of Livestock and Animal Health). 2018. Livestock and Animal Health Statistics 2018. Ministry of Agriculture Republic of Indonesia, Jakarta.

7. Felton-Taylor, J., Prosser, K.A., Hernandez-Medrano, J.H., Gentili, S., Copping, K.J., Macrossan, P.E. and Perry, V.E. 2020. Effect of breed, age, season and region on sperm morphology in 11,387 bulls submitted to breeding soundness evaluation in Australia. Theriogenology, 142: 1-7.

8. Isnaini, N., Wahjuningsih, S. and Adhitama, E. 2019a. Seasonal effects on semen quality of Ongole crossbred and Simmental bulls used for artificial insemination. Livestock Research for Rural Development, 31, p.16.

9. Isnaini, N., Wahjuningsih, S., Ma'ruf, A. and Witayanto, D.A. 2019. Effects of age and breed on semen quality of beef bull sires in an Indonesian artificial insemination center. Livestock Research for Rural Development, 31, p.78.

10. Isnaini, N., Ihsan, M.N. and Wahjuningsih, S. 2019c. Mangosteen peel extract in Tris-egg yolk extender improves fertility of cryopreserved goat sperm. Livestock Research for Rural Development, 31, p.53

11. Murphy, E.M., Kelly, A.K., O'Meara, C., Eivers, B., Lonergan, P. and Fair, S. 2018. Influence of bull age, ejaculate number, and season of collection on semen production and sperm motility parameters in Holstein Friesian bulls in a commercial artificial insemination centre. Journal of Animal Science, 96(6): 2408-2418.

12. Perumal, P. 2014. Scrotal circumference and its relationship with testicular growth, age, and body weight in Tho Tho (Bos indicus) bulls. International Scholarly Research Notices, 2014, p.249537.

13. Perumal, P., Savino, N., Sangma, C.T.R., Chang, S., Sangtam, T.Z.T., Khan, M.H., Singh, G., Kumar, B., Yadav, D. and Srivastava, N. 2017. Effect of season and age on scrotal circumference, testicular parameters and endocrinological profiles in mithun bulls. Theriogenology, 98: 23-29.

14. Rehman, H., Alhidary, I.A., Khan, R.U., Qureshi, M.S., Sadique, U., Khan, H. and Yaqoob, S.H. 2016. Relationship of age, breed and libido with semen traits of cattle bulls. Pakistan Journal of Zoology, 48(6): 1793-1798.

15. Snoj, T., Kobal, S. and Majdic, G. 2013. Effects of season, age, and breed on semen characteristics in different Bos taurus breeds in a 31-year retrospective study. Theriogenology, 79(5): 847-852.

16. Susilawati, T., Ratnawati, D., Isnaini, N., Kuswati and Yekti, A.P.A. 2018. Character of liquid semen motility in various diluents on Balinese cattle during cold storage. Asian Journal of Microbiology, Biotechnology, and Environmental Sciences, 20(1): 166-172.

17. Sutarno, Setyawan, A.D. and Lymbery, A.J. 2015. Genetic diversity of five Indonesian native cattle breeds at microsatellite loci. Asian Journal of Animal Sciences, 9(2): 57-64.

18. Widyas, N., Prastowo, S., Widi, T.S.M. and Baliarti, E. 2018. Predicting Madura cattle growth curve using non-linear model. In IOP Conference Series: Earth and Environmental Science, 142(1), p.012006. 